\section{Scale Imparity In The Financial Specialists' Hazard Avoidance And Conduct Heterogeneity}

1 Mohamed Habib,

${ }^{2}$ Akremi Houssem
1,2Institute Of Higher Business Studies, Tunis University, Tunisia

\begin{abstract}
G OPEN ACCESS
The American Journal of Social Science And Education Innovations JULY 2020

Page No.: 84-88

Volume-II Issue-VII

PUBLISHED: 30 JULY 2020 www.usajournalshub.com/inde x.php/tajssei

Copyright: Original content from this work may be used under the terms of the Creative Commons Attribution 4.0 licence.
\end{abstract}

\title{
Abstract
}

We explain at first the components constitutive of the hazard avoidance. The considered on-screen characters are singular leaders. The handled inquiries are the hazard mentality, its discernment, its assessment, the dynamic in unsafe universe. We propose a system of examination for the investigation of the financial specialists' inclinations dependent on an operational econometric demonstrating. The assessed models are the arranged probit and the arranged probit with irregular impact.

Keywords: hazard avoidance, conduct money, trial economy, lotteries, requested probit decision model, irregular impacts orderdprobit decision model.

\section{Introduction}

The investigation of the monetary division and examination of the practices of the people who work, stir today an enthusiasm developing of halfway with the ongoing patterns in the capital market. Despite the fact that the repugnance with hazard is a key factor, deciding the speculators' conduct is hard to thoroughly quantify the hazard avoidance with 
regards to monetary ventures. To be sure, the hazard avoidance is communicated by two measurements, one monetary identified with the liquidity or the soundness of the salary, the other emotional one communicated the mental fitness of the financial specialist to be lost. One of the central troubles in the estimation of repugnance for the hazard is identified with its emotional nature that can be estimated uniquely by utilizing the surveys attempting to catch the deciding components in the financial specialists' conduct. Most of the assessment techniques for the hazard avoidance created right now lay on models, which explicitly assume a linearity between subordinate variable and logical factors. Such models can't be sufficient since one assesses emotional nature of hazard avoidance. By and by, the methodology generally utilized by the money related mediators is that of the scoring3 question. The budgetary organizations proposeto their clients a modest number (from 3 to 6 ) of standard wallets, which are situated along a one-dimensional size of hazard. An ideal position relates to the minimization of the normal of the expense for the financial specialists who don't approach a wallet completely customized.

The creativity of this augmentation is as it applies too to the normal utility model as with the non-anticipated utility model, by presenting the heterogeneity of people, by having plan of action to the board methods to gauge how the hazard avoidance differs simultaneously among people and, for a similar individual, for a few circumstances of decision. All the more accurately, we proposeto loosen up the prohibitive suspicion of the unicity of the conduct boundaries all in all of financial specialists. Minks to welcome an extra lighting on the job of individual heterogeneity in the estimation of the hazard avoidance. So as to control this individual heterogeneity, we do a review which gauges and evaluates singular responses to the circumstances where hazard identifies with the money related venture. We measure hazard avoidance of a similar individual face to a few circumstances of decision. In hazard avoidance, there is a section explicit to the financial specialist when he completes his decisions while the other part alludes to the setting of decision. In two distinct settings, a similar individual settles on various decisions. We posture to a similar individual a few arrangement of lotteries, so as to review the hazard avoidance of a similar individual for different degrees of hazard, distinctive rising and 
different lengths from ventures.

\section{Engaging Insights}

As indicated by sum up the insights of factors in the example, we found that the example was homogeneous in nature. Without a doubt, it comprised of $51.14 \%$ men. The normal age was 27.341 years. In particular, $87.33 \%$ of the populace is at an age under 25 and $10.22 \%$ of the respondents had an age somewhere in the range of 26 and 40 years. Be that as it may, the most well-known conjugal status was the single one with $73.33 \%$ while the wedded spoke to just $18.92 \%$ in the example. Additionally, $59.26 \%$ of the respondents viewed themselves as beginners, $29.39 \%$ rather experienced, $10.35 \%$ and $1.00 \%$ experienced and experienced. The essential goal of venture is for $4.90 \%$ of respondents to leave a heritage, $4.17 \%$ for preparing, $2.47 \%$ for putting something aside for retirement, $11.10 \%$ for developing a security sleeping cushion, $17.92 \%$ to produce long haul income, $16.22 \%$ to create ordinary salary, $20.09 \%$ for purchasing or remodeling a house, $13.20 \%$ for strong products buys and $1.67 \%$ to develop their riches. Different objectives are so more outlandish that they can be extensively spoken to as an auxiliary target. With respect to style of financial specialists, $8.82 \%$ of respondents acknowledge no variances, $28.02 \%$ of respondents acknowledge transient vacillations, $53.44 \%$ of respondents acknowledge moderate changes and $9.72 \%$ of respondents acknowledge critical vacillations. During a time of rise and after misfortune, $26.07 \%$ of the respondent paid promptly, $54.63 \%$ held up a turnaround and $22.39 \%$ continued rising. Be that as it may, $19.65 \%$ of respondents have just contributed, $21.97 \%$ of respondents plan to reallocate a portion of their capital offer so as to accomplish their objective, $58.39 \%$ of respondents expect to bit by bit manufacture capital in the coming a very long time so as to accomplish their primary objective, while $0.13 \%$ didn't mean to contribute.

\section{Econometric Model}

Arbitrary Impacts Requested Probit Model When we watch populace $\mathrm{N}$ leaders probably autonomous and indistinguishable, put toward a similar entire of decision between lotteries, rises imperceptible issues of heterogeneity of the inclinations. Some portion of 
every dynamic procedure stays unquantifiable, and must be considered as irregular by the modelisator. The use of the strategies of board to the models of discrete decision will make it conceivable to gum these clamors.

\section{Change Investigation Of The Arbitrary Impacts}

So as to comprehend the components impacting on the hazard avoidance of the people, we do a difference examination on the arbitrary impacts requested probit model. This segment treat the second goal of our article: we attempt to decide whether the disparity in hazard avoidance with regards to the budgetary speculations is following contrasts will inside or between person. Our investigation comprises of a disintegration of the change of the variable subject to singular hazard avoidance, in inside individual and betweensingular segments of the detectable and undetectable parts.

\section{Understanding}

We note which the division of the clarified fluctuation is a lot more fragile than that not clarified (11.98\% against $87.99 \%)$ in the arbitrary impacts orderedprobit plan in the example. This proposes variety of the hazard avoidance of people is likely not clarified by the detectable qualities. In this manner, in the fluctuation examination with the arbitrary impacts orderedprobit model, we clarify just $11.98 \%$ of the first difference of the example, which is a fairly decent outcome. What's more, most of the clarified fluctuation must with the between-singular part with $8.42 \%$. Without a doubt, the heaviness of the clarified inside individual segment is 3.56, while the level of the between-individual clarified difference is $8.42 \%$. Concerning the not clarified some portion of the first change, we find that the inside individual fluctuation is $64.28 \%$ a lot higher, with the between-singular difference of $23.73 \%$.

\section{Conclusion}

The investigation of hazard avoidance in the practices of money related ventures involves a ruling spot in the hypothetical and observational late writing. In our work, we attempted to evaluate its significance and to decide its constitutive elements. For sure, ifthe 
examination of the monetary items were to a great extent rewarded, the investigation of the mentality of the financial specialist specifically his mental inclination to face challenges, stays minimal misused. So as to give a record of specific deviations contrasted with the hypothesis of anticipated utility, we presented singular heterogeneity. For sure, a similar individual went up against with indistinguishable conditions answers in an unexpected way, similar inquiries during various events. The old style hypothesis of expected utility can't togive a record of this basic perception. We can contend that these varieties of practices can be considered as blunders, present in any information obtaining.

\section{References}

1. Chisum WJ(1994), Examination of Separated Markets with Discrete Decision Models, 123 p.

2. Bates, R. and Collier, P. (1999), Inclination Boundaries and BihavioralHeterogeneity:An trial approch in the wellbeing and retirement review, Quarterly Diary of Financial aspects, vol.2, n.4, pp. 137-180.

3. Chazan, N. Mutimer R, (2005), Crossover Decision Models : Progress and Difficulties, Showcasing Letters vol.8, n. 5, pp. 63-75.

4. Kamete, A.Y. (2003). Broadened Structure for Demonstrating Decision Conduct, Advertising Letters, vol. 5, no. 6.

5. Mazrui, A. and Okelo, O. (1995), Budgetary dynamic: Are ladies extremely more hazard disinclined?, The American Monetary Survey, vol. 19, pp. 181-185.

6. Sam Kongwa's. (2008), Fund Comportementale, Economica.

7. Seremekun, O. (2002), Mentalities on Addition and Misfortune Lotteries: A Straightforward Investigation, School of Financial Examinations.

8. Collier, P. (1985), A computationally productive quadrature strategy for the one factor multinomial probit model. Econometrica vol. 5, pp.161-164. 